Conclusion SOS, BUA and Stiffness were all strongly associated with vertebral deformities in RA patients. QUS might be an independent predictor for vertebral deformities, but this need to be evaluated in larger, prospective studies.

\section{SAT0150 MISSED DIAGNOSIS AND TREATMENT OF OSTEOPOROSIS IN ELDERLY PATIENTS WITH HIP FRACTURE}

${ }^{1} \mathrm{~J}$ Iborra, ${ }^{2} \mathrm{E}$ Pagès, ${ }^{2} \mathrm{~S}$ Rodríguez, ${ }^{2} \mathrm{~A}$ Cuxart. ${ }^{1} I+D$ Novartis; ${ }^{2}$ Rehabilitation Medicine, Vall $d^{\prime}$ Hebron Hospitals, Barcelona, Spain

10.1136/annrheumdis-2001.637

Background Physicians can recognise and treat osteoporosis before the occurrence of fracture. Unfortunately, there is ample evidence that clinicians have not heard or heeded the message that condition is treatable, and that selected patients, particularly those who have already suffered a fracture, should be counselled to received preventive therapy. ${ }^{1}$ Epidemiologic studies have demonstrated that a history of osteoporotic fracture places a patient at very high risk of future fractures. ${ }^{2}$

Objectives The purpose of this study was to investigate whether elderly patients admitted to our hospital with a principal diagnosis of hip fracture had a prior diagnosis of osteoporosis or a previous osteoporotic fracture and their previous prescribed treatment.

Methods We performed a prospective chart review of all elderly $(>=65$ years) patients admitted with the diagnosis of acute hip fracture in a public hospital in Barcelona, Spain, from January 1, 1999, to December 31, 2000. Data were collected by interviewing each patient immediately after their fracture with a structured questionnaire including patient age, sex, residence, the number, type and causes of fractures, as well as previous history of osteoporosis or osteoporotic fracture, and previous treatment for osteoporosis.

Results A total of 741 patients were included. Mean age was 81.54 (range 65-103) and $74.14 \%$ were women. Six hundred seven $(81.91 \%)$ patients were admitted from their own home. Thirty $(4.05 \%)$ patients had other associated fracture; the most common was a subcapital humeral fracture, which occurred in 13 patients. There were 447 (60.32\%) extracapsular fractures. A fall was the most common cause of hip fracture $(94.87 \%$ of cases). A prior diagnosis of osteoporosis was recorded in 50 (6.74\%) patients; of them 23 (46\%) were using calcium, vitamin $\mathrm{D}$, alendronate or calcitonin. A history of hip, vertebral, wrist or another osteoporotic fracture, was recorded in 221 (29.82\%) patients but only $18(8.14 \%)$ were using any treatment for osteoporosis. Moreover 66 patients $(8.91 \%)$ had suffered from more than one fracture. Forty-seven patients (6.34\%) were on long term systemic steroids treatment for 6 months or more; ten $(21,28 \%)$ were treated with calcium, vitamin $\mathrm{D}$, alendronate or calcitonin. Eight patients admitted with a hip fracture in 1999 had a second hip fracture in 2000 , but only two were receiving preventive therapy.

Conclusion Rates of utilisation of pharmacological treatment for osteoporosis were low. Prior diagnosis of osteoporosis was the condition that implied a better (less than half) preventive treatment, but clinicians dis not consistently initiate treatment for skeletal fragility after one or more fractures had occurred.

\section{REFERENCES}

1 Bauer DC. Osteoporotic fractures: ignorance is bliss?. Am J Med. 2000;109:3389
2 Cummings SR, et al. Risk factors for hip fracture in white women. Study of Osteoporotic Fractures Research Group. N Engl I Med. 1995;332:767-73

\section{SAT0151 DIAGNOSTIC CRITERIA OF OSTEOPOROSIS IN PATIENTS WITH RA}

${ }^{1} \mathrm{~S}$ Sohen, ${ }^{1} \mathrm{M}$ Kamiya, ${ }^{1} \mathrm{M}$ Ueno, ${ }^{2} \mathrm{H}$ Kikuchi, ${ }^{3} \mathrm{~T}$ Nonaka, ${ }^{3} \mathrm{~T}$ Hamanishi. ${ }^{1}$ Orthopaedic Surgery and Rheumatology, Nara Hospital, Kinki University School of Medicine, Ikoma; ${ }^{2}$ Orthopaedic Surgery, Sakai Hospital, Kinki University School of Medicine, Sakai; ${ }^{3}$ Orthopaedic Surgery, Kinki University School of Medicine, Osakasayama, Japan

10.1136/annrheumdis-2001.638

Background We reported that generalised bone loss was observed in rheumatoid arthritis (RA), especially in post menopausal patients and closely correlate with the activity of RA. On the other hand, glucocorticoids are used in the treatment of active patients with RA. Osteoporosis and related fractures are one of the most serious adverse effects of glucocorticoids.

Objectives Recommendations for the prevention and treatment of glucocorticoid-induced osteoporosis were proposed by American College of Rheumatology and UK Consensus Group. On the other hand, the diagnosis of osteoporosis in patients with RA was usually made by the diagnostic criteria of primary osteoporosis. The purpose of the present study was to clarify the validity of using the diagnostic criteria of primary osteoporosis for the diagnosis of osteoporosis in RA.

Methods The cutoff values were defined as the value by which the subjects with spine fracture were discriminated from those without spine fracture efficiently in terms of sensitivity and specificity. The subjects and measurement of bone mineral density (BMD) were follows: number of subjects; 256 (47 with vertebral fracture, 219 without vertebral fracture), age of subjects (mean $\pm \mathrm{SD}$ ); fracture group $64.2 \pm 9.0$ years, non fracture group $59.8 \pm 10.9$ years, measured site (type of machine); lumbar spine (QDR). Patients treated with glucocorticoid were follows: number of subjects; 103(29 with vertebral fracture, 74 without vertebral fracture), Age of subjects (mean $\pm \mathrm{SD}$ ); fracture group $65.1 \pm 12.5$ years, non fracture group $54.2 \pm 13.6$ years.

Results The cutoff value of all patients with RA was $0.711 \mathrm{~g} / \mathrm{cm}^{2}$ (T score: $-2.6, \%$ of the young adult mean (\%YAM): 70\%). This value was almost same as the cutoff value (BMD: $0.708, \%$ YAM:70\%) of osteoporosis proposed by the Japanese diagnostic criteria of primary osteoporosis and as the cutoff value (T score below -2.5) of osteoporosis proposed by the WHO diagnostic criteria. On the other hand, the cutoff value in the patients treated with daily doses of $7.5 \mathrm{mg}$ or more prednisolone was $0.812 \mathrm{~g} / \mathrm{cm}^{2}$ (T score: $-1.7, \%$ YAM: $80 \%$ ). This value was almost same as the value of osteopenia by the Japanese diagnostic criteria (\%YAM below 80\%) and by the WHO diagnostic criteria (T score below -1.0).

Conclusion These results supported the validity of using the diagnostic criteria of primary osteoporosis for the diagnosis of osteoporosis in patients with RA. But, in patients treated with daily doses of $7.5 \mathrm{mg}$ or more prednisolone, we have to start the treatment for preventing bone loss, if the patients are diagnosed for osteopenia using the diagnostic criteria of primary osteoporosis. 


\section{SAT0152 EFFECTS OF RALOXIFENE ON BONE MINERAL DENSITY AND ON SERUM LIPIDS IN POSTMENOPAUSAL WOMEN WITH SEVERE OSTEOPENIA AND/OR OSTEOPOROSIS}

A Matsoyka, E Kantaxaki, S Zerboudis, A Georgiadis. Osteoporosis Center, Gynecological Hospital "LITO", Athens, Greece

\subsection{6/annrheumdis-2001.639}

Background Raloxifene (RLX) is a selective oestrogen receptor modulator (SERM) and exerts a positive estrogenic activity on bone and on serum lipids. The purpose of this randomised study was to access the effect of RLX on Bone Mineral Density (BMD) and on serum lipids in postmenopausal (PM) women with severe osteopenia and/or osteoporosis according to WHO criteria.

Objectives $100 \mathrm{PM}$ women were randomly assigned to either RLX $60 \mathrm{mg} /$ day $+600 \mathrm{mg}$ Calcium Carbonate (CC) (70 women) or $600 \mathrm{mg}$ of CC alone (30 women), as controls, for 12 months. The two groups of women had similar anthropometric data, mean age $(56,98 \pm 5,1 \mathrm{yrs})$ and mean postmenopausal age $(9,4$ $\pm 5,2$ yrs).

Methods BMD was measured at baseline and at 12 months of therapy, using DEXA (Hologic 1000 QDR) at Lumbar Spine (LS) and Lft Femur (FN)(neck). Serum total Cholesterol, LDL, HDL, triglycerides were measured at baseline, 6 and 12 months (photometric method). Results are expressed as percentage change from baseline. Statistics were done using t-test (unpaired).

Results Bone loss prevented only in the group of RLX. The BMD increased at LS $=+2,3( \pm 2,8) \%$ and at $\mathrm{FN}=1,4( \pm$ $2,6) \%$. In the group of controls the BMD diminished at LS $-1,2$ $( \pm 1,1) \%$ and at $\mathrm{FN}-1,5( \pm 2,4) \%$. The difference in BMD changes between the two groups was significant $(\mathrm{p}<0,05)$. There was no change in HDL, LDL and triglycerides in either group. Only Total Cholesterol decreased significantly $(\mathrm{p}<0,05)$ in RLX group. No clinically relevant effects on safety parameters (liver enzymes, hematologic variables and vital signs) were recorded.

Conclusion We conclude that RLX proved to be effective and safe in the prophylaxis and treatment of postmenopausal severe osteopenia and/or osteoporosis.

\section{SAT0153 VERTEBRAL DEFORMITIES IN RHEUMATOID ARTHRITIS: THE OSLO, TRURO, AND AMSTERDAM COLLABORATIVE STUDY}

${ }^{1} \mathrm{MC}$ Lodder, ${ }^{2} \mathrm{G}$ Haugeberg, ${ }^{1} \mathrm{WF}$ Lems, ${ }^{2} \mathrm{RE}$ Orstavik, ${ }^{1} \mathrm{BA}$ Dijkmans, ${ }^{2} \mathrm{TK}$ Kvien, ${ }^{3} \mathrm{AD}$ Woolf. ${ }^{1}$ Rheumatology, Vrije Universiteit Medical Centre, Amsterdam, The Netherlands; ${ }^{2}$ Rheumatology, Diakonhjemmet Hospital, Oslo, Norway; ${ }^{3}$ Rheumatology, Royal Cornwall Hospital, Truro, UK

\subsection{6/annrheumdis-2001.640}

\section{Background}

Objectives To determine the occurrence of vertebral deformities (VD) in a cross-sectional study of postmenopausal women with rheumatoid arthritis (RA). Secondly, associates for VD will be identified.

Methods A total of 150 female patients (50 per centre), aged between 50 and 70 years and a disease duration of 5 or more years, attending a general rheumatology clinic were consecutively included. Demographic and clinical data were collected according to a standardised procedure; bone fracture history, disease activity measures, hand X-rays (Larsen) and bone mineral density by means of dual energy X-ray absorptiometry of hip and lumbar spine. Lateral X-rays of thoracal and lumbar spine were read by one observer. Assessment was done as proposed by Genant. ${ }^{1}$ Associations between the presence of VD, and demographic, clinical and BMD variables were examined bivariately. The multivariate analysis was carried out using logistic regression.

Results Spine X-rays of 137 women were included in the analysis. Of these women 20 out of $137(14.6 \%)$ had at least one VD grade one or higher; $18 \%$ in Oslo, $10 \%$ in Amsterdam, and $16 \%$ in Truro. The table shows results of the bivariate analysis. Ever use of corticosteroids was not associated with VD ( $\mathrm{p}=$ $0.33)$.

Previous non-vertebral fracture after age 25 (as recalled by the patient) was the independent associate for VD in a logistic regression model containing age, weight, total Larsen score, nonvertebral fracture after age 25 and either femoral neck or spine BMD. Femoral neck BMD was independent variable in a model with age, weight, total Larsen score and femoral neck BMD. Age was the only independent associate of VD if femoral neck BMD was replaced by spine BMD in the latter model. The inclusion of corticosteroid use in either one of the models did not change the results.

\begin{tabular}{llllll}
\multicolumn{7}{c}{ Abstract SAT0153 Table 1 } \\
\hline $\begin{array}{l}\text { Age } \\
\text { (years) }\end{array}$ & $\begin{array}{l}\text { Non-vertebral } \\
\text { fracture }(\%)\end{array}$ & $\begin{array}{l}\text { Total Larsen } \\
\text { score } \\
(0-120)\end{array}$ & $\begin{array}{l}\text { Femoral neck } \\
\text { BMD }\left(\mathbf{g} / \mathrm{cm}^{2}\right)\end{array}$ & $\begin{array}{l}\text { Spine BMD } \\
\left(\mathbf{g} / \mathrm{cm}^{2}\right)\end{array}$ \\
\hline no & 60.7 & 21.6 & 37.9 & 0.81 & 1.07 \\
VD & & & & & \\
VD & 64.4 & 55.0 & 53.4 & 0.70 & 0.98 \\
p- & 0.009 & 0.02 & 0.03 & 0.006 & 0.05 \\
value & & & & & \\
\hline
\end{tabular}

Conclusion VD in a clinic population of RA patients was associated with either previous clinical fracture, femoral neck BMD or age as single independent variable dependent on the regression model applied. Studies on more patients allowing for larger regression models should further clarify the true associates of VD.

\section{REFERENCE}

1 Genant HK, et al. J Bone Miner Res. 1993;9:1137-48

\section{SAT0154 BISPHOSPHONATES AND UPPER GI PROBLEMS - WHAT IS THE EVIDENCE?}

${ }^{1}$ DC Bauer, ${ }^{2} \mathrm{~B}$ Cryor. ${ }^{1}$ Prevention Sciences Group, University of California, San Francisco, USA; ${ }^{2}$ University of Texas Southwestern Medical School, Dallas, USA

\subsection{6/annrheumdis-2001.641}

Background Upper gastrointestinal (UGI) tract mucosal irritation has been reported for a variety of bisphosphonates, including pamidronate, etidronate, clodronate, alendronate (ALN), tiludronate, and risedronate (RIS).

Objectives To use evidence-based medicine to rate and summarise the evidence regarding bisphosphonates and UGI problems. Methods Review and interpretation of published studies.

Results Although the clinical relevance of short-term, transient endoscopic findings is uncertain, one endoscopic study reported a higher incidence of gastric lesions for ALN vs RIS, and others reported no difference for ALN vs RIS or placebo. ${ }^{1-4}$ These 